\title{
Field evaluation of talc formulation of Trichoderma for the management of Fusarium wilt in watermelon
}

\author{
R. RAMESH* and N.P. SINGH \\ ICAR-Central Coastal Agricultural Research Institute, Old Goa 403 402, Goa, India
}

Received: 1 December 2016/ Accepted: 9 February 2017/ Published online: 23 March 2017

(C) Indian Phytopathological Society 2017

\begin{abstract}
Wilt of watermelon caused by Fusarium oxysporum. f.sp. niveum is one of the major constraints in watermelon production in coastal regions. In this study, twenty seven isolates of Trichoderma were evaluated for their ability to inhibit the pathogen growth. Talc formulations of four selected Trichoderma isolates were evaluated in the field. Incidence of wilt in the biocontrol treatments was less than 10 per cent in trial 1 and less than seven percent in trial 2 and less than four per cent in trial 3 during 2012-13 while control plot recorded 21 to 34 per cent incidence. During 2013-14, incidence of wilt was less than seven per cent in trial 1 and less than 15 percent in trial 2 in the biocontrol treatments while control plot recorded 19 and 28 per cent incidence. From the pooled data of all the five trials it was observed that 70 to 80 per cent reduction of wilt and 27 to 30 per cent increase in number of fruits in biocontrol treated plots over untreated control. From the study, it is concluded that seedling drench with talc formulation of Trichoderma reduced Fusarium wilt and increased yield in watermelon.
\end{abstract}

Keywords: Fusarium oxysporum, Fusarium wilt, Trichoderma, watermelon

Fusarium wilt is one of the most important diseases of watermelon and is caused by Fusarium oxysporum. f.sp. niveum. Fusarium wilt of watermelon has been reported in all countries where watermelon is cultivated (Egel and Martyn, 2013). Yield losses due to Fusarium wilt has increased (Everts and Himmelstein, 2015) and incidence was higher in the fields where cultivation was taken in successive years (Wu et al., 2013). In India, watermelon wilt was first reported in 1955 in Thane district of Mumbai and the causal agent was identified as F. oxysporum f.sp. niveum (Hegde and Bhide, 1958). In Coastal regions of Goa, watermelon is cultivated in rice fallows during rabi season. Farmers use local non-descript varieties and improved hybrids. In both the cases incidence of Fusarium wilt was reported; yield and economic loss is high. Early reports on survival of $F$. oxysporum f.sp. niveum in soil indicated that the fungus persisted for 16 years (Martyn, 2014) primarily as thick-walled chlamydospores.

Crop rotation has been traditionally practiced to manage wilt in watermelon. Rotation with non-host crops whose root exudates do not stimulate the spore germination might suppress $F$. oxysporum f.sp. niveum (Everts and Himmelstein, 2015). Crop rotation with noncucurbitaceous crops reduced the population of $F$. oxysporum f.sp. niveum (Naik and Sen, 2002). Fallowing also reduced the population of this fungus (Wu et al., 2013). Grafting on non-host cucurbits has been successful in controlling wilt of watermelon in many countries (Davis et al., 2008; King et al., 2008) and

\footnotetext{
${ }^{*}$ Corresponding author: r.ramesh @ icar.gov.in
}

grafting reported to be effective in eliminating Fusarium wilt (Keinath and Hassell, 2014).

Use of chemicals for management of Fusarium wilt had been mainly restricted to the fumigant, Methyl bromide (MeBr) (King et al., 2008) and to a lesser extent 1, 3-dichloropropene and metam sodium. However, $\mathrm{MeBr}$ use has been discontinued due to environment and other regulatory concerns. Efforts have sought non-fumigant alternatives to MeBr use (Antoniou et al., 2014). Alternative soil fumigants are not as effective as $\mathrm{MeBr}$ at controlling wilt. They are expensive and also negatively impact environment (Sande et al., 2011). Application of fungicides viz. prothioconazole, acibenzolar-S-methyl, and thiophanate-methyl had resulted into less incidence of Fusarium wilt of watermelon (Everts et al., 2014).

Biological control is one of the promising, effective and eco-friendly methods of control of Fusarium wilt. Antagonists (Fravel et al., 2005) as well as compost amendments (Boulter-Bitzer et al., 2006) have been used but with inconsistent results. Several organisms such as Penicillium oxalicum (De Cal et al., 2009), Paenibacillus polymyxa (Wu et al., 2009), Pseudomonas fluorescens, P. chlororaphis (Tziros et al., 2007) and species of Trichoderma (Pandey and Gupta, 2012) have been evaluated for Fusarium wilt suppression. Trichoderma species are soil inhabitants, competitive saprophytes, and facultative mycoparasites that can colonize the soil and rhizosphere (Harman et al., 2004). Trichoderma spp. are the most widely studied biological control agents for soil borne diseases and are also applied in post-harvest disease managaement (Woo et al., 2014). 

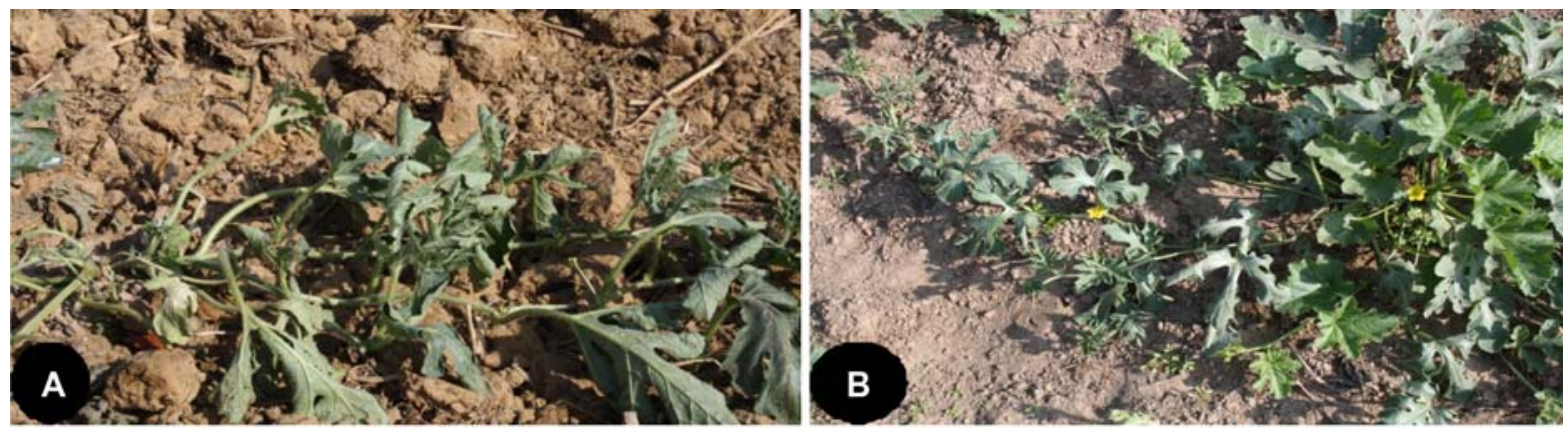

Fig. 1. Wilting of watermelon plant (A: complete wilt; B: partial wilt)

In some countries, watermelon seeds were treated with biocontrol agents and the seedlings were also applied with biocontrol agents during transplanting (Tziros et al., 2007). However in India, the seeds were directly sown in the field, hence we tried the seedling drench instead of seedling dip. The aim of the present study was to assess the antagonistic features of isolates of Trichoderma and their efficacy in controlling Fusarium wilt in watermelon, in order to design an effective biological control strategy.

\section{MATERIALS AND METHODS}

\section{Isolation of F. o. f.sp. niveum}

F. oxysporum f. sp. niveum was isolated from infected watermelon plants (Augusta-Hybrid from Syngenta and local non- descript type), grown in an open field. The first visible symptom of Fusarium wilt in watermelon is partial wilting of the plant i.e. one side of a plant wilts (Fig. 1). Roots of the infected plant are white, but the vascular tissue is brown and discolored (Fig. 2). F. oxysporum f. sp. niveum was consistently isolated from the base of the plant/ roots on potato dextrose agar (PDA) medium and cultures were routinely grown on PDA. Fusarium was identified morphologically as F. oxysporum by the thick walled chlamydospore production and colonies forming microconidia on short monophialides. The susceptible local variety was inoculated with single spore cultures and all plants developed typical Fusarium wilt, often one sided and the Fusarium was re-isolated. Pathogenicity tests demonstrated that the F. oxysporum fungus caused wilt on inoculated watermelon plants, and so by definition is F. oxysporum f.sp. niveum. Inoculated plants wilted in eight to 30 days after inoculation.

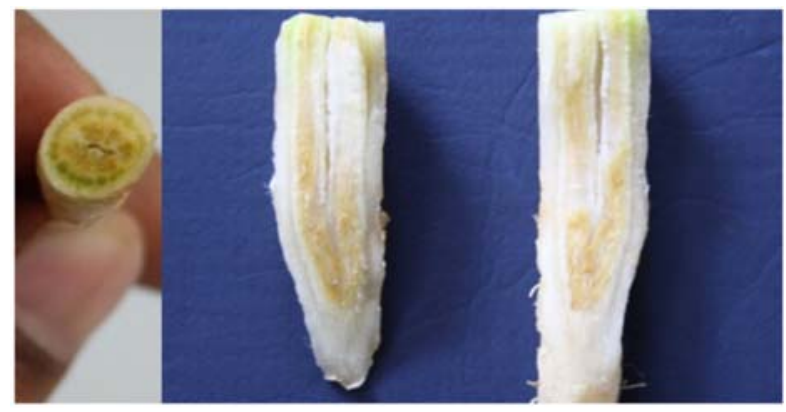

Fig. 2. Browning of vascular tissues in the wilt affected watermelon root

\section{Screening of Trichoderma isolates for the inhibition of F. o. f.sp. niveum}

Antagonistic properties of 27 selected isolates of Trichoderma (Table 1) were tested on PDA plates using a dual culture technique. Fifteen isolates were obtained from ICAR-IISR, Kozhikode under the PhytoFuRa project and 10 isolates were obtained from ICAR-PDBC (Now NBAIR), Bengaluru. Five days old mycelial discs $(7 \mathrm{~mm})$ of the pathogen was placed on one side of the Petri dish and a disc of Trichoderma growth $(7 \mathrm{~mm}$ dia) of four days old was placed on the opposite side of the plate and incubated at $28 \pm 2{ }^{\circ} \mathrm{C}$ for 4 days for initial observation. Final observation on antagonism was recorded after 10 days of incubation. Diameter of Trichoderma growth and pathogen growth were recorded. Further, inhibition zone created by Trichoderma was also recorded.

\section{Field evaluation of talc formulation of promising Trichoderma isolates}

Based on the in vitro evaluation, four strains of Trichoderma (Pf2, Pf3, TA23 and Tv1) were selected for field evaluation for the management of wilt in watermelon. Talc based formulation of the Trichoderma was prepared according to the standard method (Ramesh and Korikanthimath, 2006). Population of Trichoderma at the time of application was about $10^{7} \mathrm{CFU} \mathrm{g^{-1 }}$.

One week-old watermelon plants were treated by drenching the water suspension of biocontrol formulation @ 1.25g per plant. Carbendazim was used @ $0.1 \mathrm{~g}$ per plant. During 2012-13, three field trials were conducted; two trials with Augusta hybrid and one trial with local variety. During 2013-14, two trials were conducted using Augusta hybrid. All experiments were conducted in RBD with 4 replications. Mean plot size was $32 \mathrm{~m}^{2}$ and twenty plants per replication were maintained with $1 \times 1 \mathrm{~m}$ spacing. Standard crop management practices were followed in all the trials. Incidence of wilt was recorded periodically and number of fruits per plot was recorded.

\section{RESULTS}

Screening of Trichoderma isolates for the inhibition of F. o. f.sp. niveum

Twenty seven Trichoderma isolates were used in the study. In vitro screening indicated that, most of the 
Table 1. Details of Trichoderma isolates used and their in vitro inhibitory potential against $F$. oxysporum f.sp. niveum

\begin{tabular}{|c|c|c|c|}
\hline Isolates & Source & Growth of FON (cm) & $\%$ inhibition of FON over control \\
\hline PhytoFuRa 1(Pf1) & ICAR-IISR, Kozhikode & 3.0 & 66.7 \\
\hline PhytoFuRa 2 (Pf2) & ICAR-IISR, Kozhikode & 1.2 & 86.7 \\
\hline PhytoFuRa 3 (Pf3) & ICAR-IISR, Kozhikode & 0.6 & 93.3 \\
\hline PhytoFuRa 4 (Pf4) & ICAR-IISR, Kozhikode & 2.1 & 76.3 \\
\hline PhytoFuRa 5 (Pf5) & ICAR-IISR, Kozhikode & 1.0 & 88.5 \\
\hline PhytoFuRa 6 (Pf6) & ICAR-IISR, Kozhikode & 0.0 & 100.0 \\
\hline PhytoFuRa 7 (Pf7) & ICAR-IISR, Kozhikode & 3.4 & 62.6 \\
\hline PhytoFuRa 8 (Pf8) & ICAR-IISR, Kozhikode & 2.1 & 77.0 \\
\hline PhytoFuRa 9 (Pf9) & ICAR-IISR, Kozhikode & 0.0 & 100.0 \\
\hline PhytoFuRa 10 (Pf10) & ICAR-IISR, Kozhikode & 0.0 & 100.0 \\
\hline PhytoFuRa 11 (Pf11) & ICAR-IISR, Kozhikode & 0.0 & 100.0 \\
\hline PhytoFuRa 12 (Pf12) & ICAR-IISR, Kozhikode & 0.0 & 100.0 \\
\hline PhytoFuRa 13 (Pf13) & ICAR-IISR, Kozhikode & 0.0 & 100.0 \\
\hline PhytoFuRa 14 (Pf14) & ICAR-IISR, Kozhikode & 0.0 & 100.0 \\
\hline PhytoFuRa 15 (Pf15) & ICAR-IISR, Kozhikode & 2.5 & 72.6 \\
\hline NABII-TA10 & ICAR-NBAIR, Bengaluru & 0.0 & 100.0 \\
\hline NABII-TA23 & ICAR-NBAIR, Bengaluru & 0.0 & 100.0 \\
\hline NABII-TH10 & ICAR-NBAIR, Bengaluru & 0.9 & 90.4 \\
\hline NABII-TH07 & ICAR-NBAIR, Bengaluru & 1.5 & 83.0 \\
\hline NABII-TH19 & ICAR-NBAIR, Bengaluru & 0.8 & 91.5 \\
\hline NABII-TH09 & ICAR-NBAIR, Bengaluru & 1.3 & 85.2 \\
\hline NABII-TVS05 & ICAR-NBAIR, Bengaluru & 1.1 & 87.4 \\
\hline NABII-TVS08 & ICAR-NBAIR, Bengaluru & 0.0 & 100.0 \\
\hline NABII-TVS12 & ICAR-NBAIR, Bengaluru & 1.2 & 87.0 \\
\hline NABII-TH16 & ICAR-NBAIR, Bengaluru & 1.2 & 86.7 \\
\hline TV1 & ICAR-CCARI, Goa & 0.0 & 100.0 \\
\hline TV2 & ICAR-CCARI, Goa & 1.8 & 79.6 \\
\hline Control & & 9.0 & 0.0 \\
\hline CD (0.05) & & 0.182 & - \\
\hline CD (0.01) & & 0.243 & - \\
\hline
\end{tabular}

${ }^{*}$ Mean of three replications. FON: F. oxysporum f.sp. niveum

isolates inhibited the pathogen growth (Table 1). Results revealed that out of 27 Trichoderma cultures seven isolates viz. Pf 2, Pf3, Pf 10, Pf 13, TA 23, TH-10, TH-7, TVS 08 and TV1 effectively inhibited pathogen growth in repeated assays. Based on the fast growth, sporulation and parasitism of the pathogen four isolates viz. Pf2, Pf3, TA-23 and TV1 were selected for making formulation and testing in the field.

\section{Field evaluation of talc formulation of promising} Trichoderma isolates

Results of field trials during 2012-13 indicated that biocontrol treatments reduced the incidence of wilt and increased the number of fruits. Incidence of wilt in the biocontrol treatments is less than 10 per cent in trial 1 and less than 7 percent in trial 2 and less than 4 per cent in trial 3. Plants treated with $\mathrm{Pf} 2$ recorded the least wilt incidence $(5.35 \%, 3.88 \%$, and $1.39 \%)$ followed by Tv1 treatment $(6.26 \%, 4.88 \%$ and $2.08 \%)$ in all the trials. Wilt incidence in biocontrol treatments was significantly less compared to control plot which recorded 21-34\% incidence. Number of fruits per plot in biocontrol treatments ranged between 42-46 in trial 1; 53-59 in trial 2 and 72-76 in trial 3. Higher number of fruits per plot was recorded in Pf2 treatment followed by Tv1 treatment (Table 2). Per cent reduction of wilt was $76-84 \%$ and per cent increase in number of fruits was $26-30 \%$ based on consolidated data of all the three trials during 2012-13.

Results of field trials during 2013-14 also indicated a similar trend. Incidence of wilt in the biocontrol treatments is less than seven per cent in trial 1 and less than 15 percent in trial 2. Plants treated with $\mathrm{Pf} 2$ and $\mathrm{Pf} 3$ recorded the least wilt incidence in trial 1 (2.08\%) and trial $2(10.94 \%)$ respectively. Wilt incidence in biocontrol treatments was significantly less compared to control plot which recorded $19-28 \%$ incidence. Number of fruits per plot in biocontrol treatments ranged between 47-52 in trial1 and 20-25 in trial 2. Higher number of fruits was observed in TA23 (trial 1) and Pf3 (trial 2) treatments 
Table 2. Effect of application of talc formulation of Trichoderma on wilt and yield in watermelon during 2012-13

\begin{tabular}{|c|c|c|c|c|c|c|}
\hline & \multicolumn{2}{|c|}{ Trial 1} & \multicolumn{2}{|c|}{ Trial 2} & \multicolumn{2}{|c|}{ Trial 3} \\
\hline & $\%$ wilt & No. of fruits/ plot & $\%$ wilt & No. of fruits/ plot & $\%$ wilt & No. of fruits/ plot \\
\hline Tv1 & 6.26 & 44.50 & 4.88 & 57.50 & 2.08 & 75.50 \\
\hline TA23 & 9.69 & 42.50 & 6.45 & 53.25 & 3.46 & 74.00 \\
\hline Pf2 & 5.35 & 46.25 & 3.88 & 59.50 & 1.39 & 76.50 \\
\hline Pf3 & 7.66 & 42.50 & 6.03 & 55.00 & 2.39 & 73.00 \\
\hline Carbendazim & 11.71 & 40.00 & 9.14 & 51.50 & 3.75 & 72.00 \\
\hline Control & 34.36 & 26.75 & 27.95 & 39.75 & 21.33 & 57.50 \\
\hline $\mathrm{CD}(0.05)$ & 5.78 & 6.19 & 10.17 & 5.50 & 9.48 & 5.94 \\
\hline
\end{tabular}

Table 3. Effect of application of talc formulation of Trichoderma on wilt and yield in watermelon during 2013-14

\begin{tabular}{lccccc}
\hline & \multicolumn{2}{c}{ Trial 1 } & & \multicolumn{2}{c}{ Trial 2 } \\
\cline { 2 - 3 } \cline { 5 - 6 } \% wilt & $\begin{array}{c}\text { No. of } \\
\text { fruits/ plot }\end{array}$ & & $\begin{array}{c}\text { No. of } \\
\text { fruits/ plot }\end{array}$ \\
\hline Tv1 & 6.25 & 47.5 & & 12.50 & 22.25 \\
TA23 & 5.21 & 52.25 & & 14.06 & 20.50 \\
Pf2 & 2.08 & 47.25 & & 12.50 & 25.00 \\
Pf3 & 4.17 & 47.5 & & 10.94 & 25.25 \\
Carbendazim & 6.25 & 45.75 & & 20.31 & 17.50 \\
\hline Control & 19.79 & 37.25 & 28.13 & 15.50 \\
CD (0.05) & 10.15 & NS & 9.62 & 6.59 \\
\hline
\end{tabular}

(Table 3). Per cent reduction of wilt was $59-70 \%$ and per cent increase in number of fruits was $24-27 \%$ based on consolidated data of both the trials during 2013-14.

Data from all the five trials were combined and the pooled mean analysis indicated that, the wilt incidence in biocontrol treated plots was less than 8 per cent $(5.04$ to $7.78 \%$ ), whereas in control it was 26.31 per cent. The number of fruits from an average 32 sq.m biocontrol treated plots ranged from 48.50 to 50.90 and it was only 35.35 in the control plot. Per cent reduction of wilt in biocontrol treated plots was 70-80 per cent and per cent increase in number of fruits was 27-30 per cent based on consolidated data of all the five trials (Table 4).

\section{DISCUSSION}

The fungus that causes Fusarium wilt in watermelon is very specific and cannot infect even closely related plants such as cucumber and muskmelon. F. oxysporum f.sp. niveum forms resilient spores that can remain viable in the soil for many years. That means Fusarium wilt may appear in a field that may not have had a suitable host for many seasons and hence crop rotation does not eliminate the problem. Soil solarization has not provided reliable results (Cebolla et al., 2000) and use of $\mathrm{MeBr}$ was discontinued as it is harmful to the environment (Song et al., 2004). Grafting on resistant rootstocks (Miguel et al., 2004) and growing of resistant varieties provides some degree of protection from Fusarium wilt, but currently commercially acceptable cultivars with adequate resistance to $F$. oxysporum f.sp. niveum is not available. Application of fungicides viz. prothioconazole, acibenzolar-Smethyl, and thiophanate-methyl had resulted less incidence of Fusarium wilt of watermelon (Everts et al., 2014). There is a need for alternative control practices for watermelon wilt and biological control is one of the potential alternatives.

Application of conidial suspension of Penicillium oxalicum reduced the incidence of Fusarium wilt in watermelon and melon (De Cal et al., 2009). In our field experiments, application of Trichoderma reduced the incidence of wilt and the difference among the isolates was not significant (Table 2 and 3). All the biocontrol treatments are at par with the chemical fungicide. Wu et al. (2009) reported that a bio-organic fertilizer containing Paenibacillus polymyxa and Trichoderma harzianum reduced Fusarium wilt of watermelon. Role of elevated activities of defense related enzymes as a result of systemic acquired resistance was attributed as mechanism of action for this disease suppression activity. Though we have not studied the mechanism of disease

Table 4. Effect of application of talc formulation of Trichoderma on wilt and yield in watermelon -pooled data of two years comprising five trials

\begin{tabular}{lcccccc}
\hline Treatments & \% wilt & $\begin{array}{c}\text { No. of fruits/ } \\
\text { plot (32 sq.m) }\end{array}$ & $\begin{array}{c}\text { No. of } \\
\text { fruits/ha }\end{array}$ & $\begin{array}{c}\text { *Total income } \\
\text { (Rs) }\end{array}$ & $\begin{array}{c}\text { \% reduction } \\
\text { of wilt }\end{array}$ & $\begin{array}{c}\text { \% increase in } \\
\text { no. of fruits }\end{array}$ \\
\hline Tv1 & 6.39 & 49.45 & 15453 & 463594 & 75.70 & 28.51 \\
TA23 & 7.78 & 48.50 & 15156 & 454688 & 70.45 & 27.11 \\
Pf2 & 5.04 & 50.90 & 15906 & 477188 & 80.84 & 30.55 \\
Pf3 & 6.24 & 48.65 & 15203 & 456094 & 76.30 & 27.34 \\
Carbendazim & 10.23 & 45.35 & 14172 & 425156 & 61.10 & 22.05 \\
\hline Control & 26.31 & 35.35 & 11047 & 331406 & 0.00 & 0.00 \\
\hline
\end{tabular}

*An average price of Rs. 30/ fruit is considered for income calculation 
control, we observed higher hyperparasitism and lysis zones due to secretion of antibiotics in the in vitro assays. Trichoderma is known to be an aggressive parasite on host fungi and secrete many antimicrobial compounds (Harman et al., 2004). There are also several reports indicating that Fusarium disease control can be improved using combinations of biocontrol organisms (Rajendran et al., 2014).

Seed treatment is an attractive method for applying biocontrol agents, as other methods require larger amounts of propagules. However, the survival of the biocontrol agent in the soil after the application is essential for the efficient control of the pathogen. Hence it would be advisable to apply the biocontrol agents during the initial stages of growth and follow it up one more time if necessary. Higher disease reduction in the biocontrol treatments in this study may be due to the higher population applied in the rhizosphere soil as seedlings were drenched. Change in the microbial communities in rhizosphere soil was attributed in suppression of Fusarium wilt in watermelon where it was intercropped with aerobic rice (Ren et al., 2008). Despite the evidence that some disease reductions can be achieved with biological products, commercial use remains very low (Fravel et al., 2005). Improving stability of the biological organisms in the intended environment and understanding causes of the occasional failure are areas of future research to develop effective disease management strategies.

\section{REFERENCES}

Antoniou PP, Tjamos EC and Giannakou JO (2014). Low-cost and effective approaches of soil disinfestation of plastic house or open field crops in Greece. Proc. Acta Hort. 1044: 29-41.

Boulter-Bitzer JI, Trevors JT and Boland GJ (2006). A polyphasic approach for assessing maturity and stability in compost intended for suppression of plant pathogens. Appl. Soil Ecol. 34: 65-81.

Cebolla B, Busto J, Ferrer A, Miguel A and Maroto JV (2000). Methyl bromide alternatives on horticultural crops. Acta Hort. 532: 237-242.

Davis AR, Perkins-Veazie P, Sakata Y, Lopez-Galarza S, Maroto JV, Lee SG, Huh YC, Sun Z, Miguel A, King SR, Cohen R and Lee JM (2008). Cucurbit grafting. Crit. Rev. Plant Sci. 27: $50-74$.

De Cal A, Sztejnberg A, Sabuquillo P and Melgarejo P (2009). Management Fusarium wilt on melon and watermelon by Penicillium oxalicum. Biol. Control 51: 480-486.

Egel DS and Martyn RD (2013). Fusarium wilt of watermelon and other cucurbit crops. Plant Health Instr. http:// dx.doi.org/10.1094/PHI-I-2007-0122-01. Online. Published.

Everts KL and Himmelstein JC (2015). Fusarium wilt of watermelon: Towards sustainable management of a reemerging plant disease. Crop Prot. 73: 93-99.

Everts KL, Egel DS, Langston D and Zhou XG (2014). Chemical management of Fusarium wilt of watermelon. Crop Prot. 66: 114-119.

Fravel DR, Deahl KL and Stommel JR (2005). Compatibility of the biocontrol fungus Fusarium oxysporum strain
CS-20 with selected fungicides. Biol. Control 34: 165169.

Harman GE, Howell CR, Viterbo A, Chet I and Lorito M (2004). Trichoderma species - opportunistic, avirulent plant symbionts. Nat. Rev. Microbiol. 2: 43-56.

Hedge RK and Bhide VP (1958). Watermelon wilt in Bombay state caused by Fusarium oxysporum f. niveum (E.F.S). S\&H. Indian Phytopath. 11: 49-52.

Keinath AP and Hassell RL (2014). Suppression of Fusarium wilt caused by Fusarium oxysporum f. sp. niveum race 2 on grafted triploid watermelon. Plant Dis. 98: 1326-1332.

King SR, Davis AR, Liu W and Levi A (2008). Grafting for disease resistance. Hort. Science 43: 1673-1676.

Martyn RD (2014). Fusarium wilt of watermelon: 120 years of research. Hortic. Rev. 42: 349-442

Miguel A, Maroto JV, San Bautista A, Baixauli C, Cebolla V, Pascual B, Lopez S and Guardiola JL (2004). The grafting of triploid watermelon is an advantageous alternative to soil fumigation by methyl bromide for control of Fusarium wilt. Sci. Hortic. 103: 9-17.

Naik MK and Sen B (2002). Management of Fusarium wilt of watermelon by rhizosphere manipulation of noncucurbitaceous crops. Indian Phytopath. 55: 95-96.

Pandey KK and Gupta RC (2012). Management of Fusarium wilt of tomato by application of bioagents and salicylic acid. Indian Phytopath. 65: 94-96.

Rajendran L, Raja P, Jagadeeswari V, Shanthi VP and Selvaraj N (2014). Pseudomonas fluorescens and Trichoderma viride enriched bioconsortium for the management of Fusarium wilt in carnation and gerbera under protected cultivation. Indian Phytopath. 67: 77-81.

Ramesh R and Korikanthimath VS (2006). Management of groundnut root rot by Trichoderma viride and Pseudomonas fluorescens under rainfed conditions. Indian J. Plant Prot. 34: 239-241.

Ren L, Su S, Yang X, Xu Y, Huang Q and Shen Q (2008). Intercropping with aerobic rice suppressed Fusarium wilt in watermelon. Soil Biol. Biochem. 40: 834-844.

Sande D, Mullen J, Wetzstein M and Houston J (2011). Environmental impacts from pesticide use: a case study of soil fumigation in Florida tomato production. Int. J. Environ. Res. Public Health 8: 4649-4661.

Song WT, Zhou LG, Yang CZ, Cao XD, Zhang, LQ and Liu XL (2004). Tomato Fusarium wilt and its chemical control strategies in a hydroponic system. Crop Prot. 23: 243-247.

Tziros GT, Lagopodi AL and Tzavella-Klonari K (2007). Reduction of Fusarium wilt in watermelon by Pseudomonas chlororaphis PCL1391 and P. fluorescens WCS365. Phytopathol. Mediterr. 46: 320-323.

Woo SL, Ruocco M, Vinale F, Nigro M, Marra R, Lombardi N, Pascale A, Lanzuise S, Manganiello $G$ and Lorito M (2014). Trichoderma-based products and their widespread use in agriculture. Open Mycol. J. 8: 71-126.

Wu HS, Gao ZQ, Zhou XD, Shi X, Wang MY, Shang XX, Liu YD, Gu DL and Wang WZ (2013). Microbial dynamics and natural remediation patterns of Fusarium infested watermelon soil under $3 \mathrm{yr}$ of continuous fallow condition. Soil Use Manage. 29: 220-229.

Wu HS, Yang XN, Fan JQ, Miao WG, Ling N, Xu YC, Huang QW and Shen $Q$ (2009). Suppression of Fusarium wilt of watermelon by a bio-organic fertilizer containing combinations of antagonistic microorganisms. Bio Control 54: $287-300$. 